Document downloaded from:

http://hdl.handle.net/10251/104445

This paper must be cited as:

Serrano, MA.; Cañada, J.; Moreno, J. (2009). Erythemal ultraviolet exposure in two groups of outdoor workers in Valencia, Spain. Photochemistry and Photobiology. 85(6):1468-1473. doi:10.1111/j.1751-1097.2009.00609.x

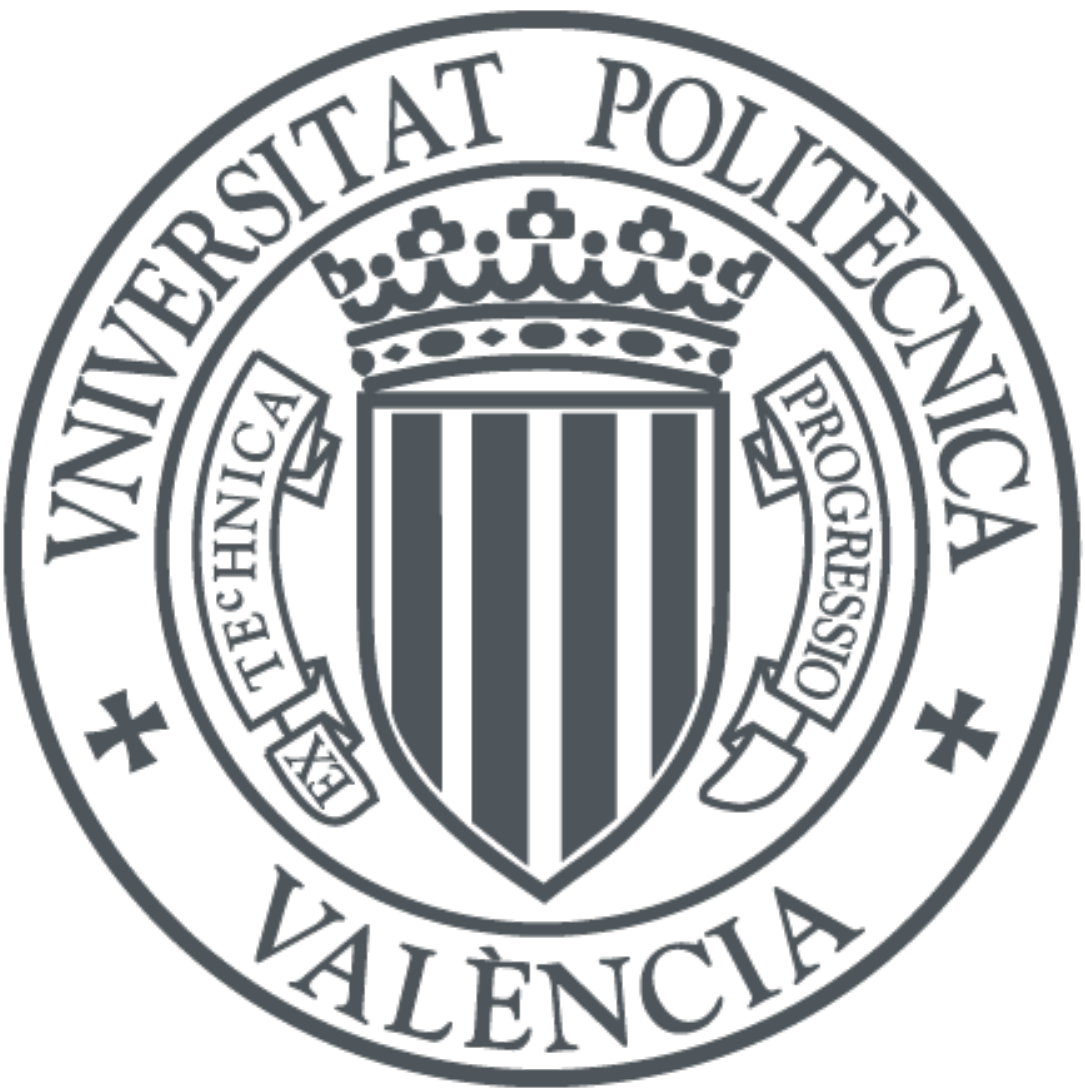

The final publication is available at

https://doi.org/10.1111/j.1751-1097.2009.00609.x

Copyright Blackwell Publishing

Additional Information 


\title{
Solar UV exposure in construction workers in Valencia, Spain.
}

\author{
María-Antonia Serrano *, Javier Cañada, Juan Carlos Moreno \\ Instituto de Ingeniería Energética, Universitat Politècnica de València, Camino de Vera s/n, \\ 46022 Valencia, España \\ Members of the Valencia Solar Radiation Research Group \\ *Corresponding author: mserranj@ fis.upv.es (Maria Antonia Serrano), \\ Tel: +34-963877007; Fax: +34-963879896.
}




\begin{abstract}
Exposure to ultraviolet radiation (UVR) has long been recognized as the most important environmental risk factor for melanoma and skin cancer. Outdoor workers are among the groups most at risk from exposure to solar UVR in their daily activities. Sensitive spore-film filter-type personal dosimeters (VioSpor) were used to measure the biologically effective UVR received by construction workers in the course of their daily work. The study took place in Valencia, Spain, in July 2010 and involved a group of 8 workers for a period of 5 days. The median UV exposure was $6.11 \mathrm{SED} /$ day, with $1 \mathrm{SED}$ defined as effective $100 \mathrm{~J} / \mathrm{m}^{2}$ when weighted with the CIE erythemal response function. These workers were found to receive a median of $13.9 \%$ of total daily ambient ultraviolet erythemal radiation (UVER). Comparison with the occupational UVR exposure limit showed that the subjects had received UVER exposure in excess of occupational guidelines, indicating that protective measures against this risk are highly advisable.
\end{abstract}




\section{Introduction}

The epidemiological and biological evidence and a large body of literature support a causal link between UVR exposure and melanoma and non melanoma skin cancers (Lucas et al., 2006).

The 2006 WHO report (Lucas et al., 2006) was the first-ever systematic examination of the global health burden attributable to UVR and researched nine adverse health outcomes from excess UVR exposure. The three most important were found to be cutaneous malignant melanomas and non-melanoma skin cancers (squamous cell carcinomas and basal cell carcinomas). UVR can also cause sunburn, skin photoageing and cortical cataracts, among others.

According to the Lucas report, the most serious consequence of excessive UVR is malignant melanoma, which has high cure rates only when detected early. Up to $90 \%$ of the global burden of disease from melanoma and other skin cancers are estimated to be due to UVR exposure (Lucas et al., 2006).

Skin cancer and melanoma are a growing problem in Spain and the rest of Europe as its incidence has increased significantly in the last 20 years (Birch et al., 2010; de Vries et al., 2003; Fuglede et al., 2011; Garbe et al., 2009; Madan et al., 2010; Medhaug et al., 2009).

Regarding non-melanoma skin cancer (NMC), there are significant variations in incidence rates between Europe, the USA and Australia: these are about 5 times higher in the USA and 20-40 times higher in Australia than in Europe (WHO, 2008). A continuous increase in incidence over time has been observed in different parts of the world, particularly in Spain, where in the period 1985-87 the age-standardised incidence rate (european standard 
population) presented for men a maximum of 72.04, while in the period 1992-98 the maximum was of 105.2 (Cabanes et al., 2009).

However, NMC, the most common malignant tumour of all, are rarely a cause of death (WHO, 2008). In Spain the NMC mortality rate has been halved in the last 35 years. This decrease in annual mortality has been confirmed in the last decade $(-2.8 \%$ in men and $-4.4 \%$ in women) (Cáncer en cifras, 2011).

Regarding melanoma, there are about 160000 new cases worldwide each year, of which almost $80 \%$ are in North America, Europe, Australia and New Zealand (WHO, 2008). In Europe, the incidence of melanoma has nearly tripled in the last 40 years at a rate of $4 \%$ per year (WHO, 2008). For melanoma, Spain presented an age-standardised incidence rate (world standard population) of 3.2 in 1985 and 5.2 in 2008 (GLOBOCAN, 2008), lower than in Europe (7.2) and Scandinavia (12.7) and of course Australia and New Zealand (36.6), with the highest figures in the world (GLOBOCAN, 2008).

Melanoma, the most aggressive cutaneous cancer, is responsible for up to $80 \%$ of all deaths from skin cancers (Lucas et al., 2006), with 60000 deaths per year worldwide caused by solar UVR.

In Spain the mortality rate from melanoma has quadrupled in the last 35 years (Cáncer en cifras, 2011), although there has only been a slight increase in annual mortality $(0.14 \%$ in men and $0.62 \%$ in women) in the last decade. Despite this increase, the mortality rate from melanoma in Spain is still among the lowest in Europe, probably due to the population's skin characteristics.

During the 90's a group of international experts (CAREX project) met to evaluate exposure to carcinogens in the workplace (Kauppinen et al., 1998) within the European Union program 
"Europe against Cancer". According to the criteria established by these experts, the highest number of cases of occupational exposure occurred in Spain (Maqueda et al., 1998). The CAREX project found that in Spain $25 \%$ of the working population, i.e. 3.1 million workers between 1990 and 1993, were exposed to agents considered to be carcinogens by the IARC (IARC, 2000; Maqueda et al., 1998). Solar radiation was the agent more important, as is main source of human exposure to UVR, with approximately 1 million workers affected between 1990 and 1993 (Maqueda et al., 1998).

It is therefore generally accepted that constant exposure to solar UVR, especially in unprotected outdoor workers, is a significant risk factor. High occupational UVR exposure is assumed to be associated with skin cancer (Bauer et al. 2011; Downs et al., 2009; Hakansson et al., 2001; Kenborg et al., 2010; Lichte et al., 2010; Radespiel et al., 2009).

Some recent studies show that the incidence of melanoma is related to both altitude and latitude (Aceituno et al. 2011; Boniol et al. 2005; Chang et al., 2009; de Vries et al., 2004; Downs et al., 2011; Micu et al., 2011; Moehrle and Garbe, 1999; Pfeifer et al., 2006).

Due to its geographical situation, for most of the year the Valencia Region (Spain) receives large doses of UVR. Outdoor workers receive regular and significant solar UVR in their course of their activities (Gies and Wright, 2003; Gies et al., 2009; Glanz et al., 2007; Hammond et al., 2009; Milon et al., 2007; Moehrle et al., 2003; Schmalwieser et al., 2010; Serrano et al., 2009; Siani et al., 2011; Siani et al., 2008; Thieden et al. 2005) especially when solar radiation is intense.

Otherwise, solar exposure is known to have positive effects on human health, such as, for example, the synthesis of Vitamin $\mathrm{D}_{3}$ (de Gruijl, 2011; Webb et al., 2011), essential for bone mineralization (Norval et al. 2007). Appropriate vitamin D levels, besides being required for 
skeletal health, have also been suggested as beneficial against multiple sclerosis (Kampman et al., 2010; Van Amerongen et al., 2004), cardiovascular disease (Zittermann and Gummert, 2010) and the development of breast, prostate and colon cancers (Gilbert et al., 2009; Grant, 2010; Grant and Holick, 2005; John et al., 2007). In the case of depressive disorders, there is evidence that supports the role of suboptimal vitamin D levels, although the data are not conclusive and further studies are necessary (Humble, 2010).

International campaigns, such as the Euromelanoma (Euromelanoma, 2011) have been set in motion to prevent and detect massive melanoma. Since the year 2000, Spain has participated in three of these campaigns, proving their value by the number of new early detections and successfully excised melanomas.

The aim of this work was to quantify the ultraviolet erythemal radiation (UVER) exposure of building workers in the course of several days in their regular work schedule during the summer in Valencia (Spain) using personal dosimeters.

\section{Materials and methods}

\section{Study location}

The study took place in the campus of the Universitat Politècnica de València (UPV) (coordinates $0^{\circ} 22^{\prime} \mathrm{W}, 39^{\circ} 28^{\prime} \mathrm{N}$, sea level) to the north of the city of Valencia, far from industrial areas and near open country, in the Spanish region of Valencia in July 2010 and involved a group of 8 building workers over a period of five working days (7, 8,9,12 and 13 July). 


\section{Subjects and design}

Subjects The subjects completed a questionnaire in which they registered the time that they put on and removed the dosimeter and the number of hours spent outdoors. As the purpose was to determine the maximum solar exposure received during their activities, they were instructed to use the dosimeters at the beginning of their working day if most of the sky was cloudless. They were also asked not to make any changes to their behaviour during the test and to continue with their normal schedules.

1) Eight male workers were selected at random from the employees of a construction company that was putting up a building on the UPV campus at the time. Their work was carried out entirely outdoors during the period of five working days. The group included: one site foreman, one formwork foreman, two security officers, three formworkers and one steel fixer. The two security officers and two formworkers wore the dosimeters on their shoulders throughout their working day, while the others wore the dosimeter on the chest.

The individual cumulative solar UVER exposure was measured by a VioSpor Type II dosimeter, which was changed every day. The subjects wore the dosimeters from 8 a.m. to 7 p.m. (except during the 2 p.m. - 3 p.m. lunch hour), except for 9 July, when it was worn from 7 a.m. to 3 p.m.

Personal UVER dosimeters A UV sensitive spore-film filter system (VioSpor Blue Line Type II Dosimeter, Bio-Sense, Bornheim, Germany) was used in the test. These dosimeters have been proved effective for personal UV measurements in outdoor occupations such as building workers (Milon et al., 2007), lifesaving (Moehrle and Garbe, 2000; O’Riordan et al., 2008; Serrano et al. 2009), or mountain guides (Moehrle et al., 2003; Moehrle and Garbe, 2000). 
Spore-film production (DNA repair-deficient strain of Bacillus subtilis) and the development of the films are described in Furusawa et al., 1998 and Munakata et al., 2000. The spore films are covered by a filter system with optical properties simulating the erythemal response of human skin, in accordance with the Commission Internationale de L'Eeclairage (CIE) reference spectrum (McKinley and Diffey, 1987) and mounted in waterproof casings with a diameter of $32 \mathrm{~mm}$. The working range used is 0.5-22.5 standard erythema dose (SED), where 1 SED is defined as effective exposure of $100 \mathrm{~J} / \mathrm{m}^{2}$ (CIE, 1997) when weighted with the CIE erythemal response function. The manufacturer declares a measurement error of $\pm 10 \%$. The measurements are expressed as SED of biologically effective solar UVR.

The VioSpor system is subject to constant quality control checks. System validation is carried out using in-vivo comparative measurements (Quintern et al., 1997). The wavelength-specific calibration of VioSpor is carried out using measurements on the Okasaki spectrograph in Japan (lamp performance based on the US radiation strength norm of the National Institute of Standards) (Furusawa et al., 1998; Munakata et al., 2000).

VioSpor has also been validated during several instrument intercomparisons performed under field conditions in which VioSpor data were compared with the minimal erythema dose values calculated from spectroradiometer data (Seckmeyer et al., 1998).

\section{Ambient solar UVER}

Ambient UVER was recorded with a UVB-1 radiometer (Yankee Environment System, YES), belonging to the Valencia regional government's (GV) UVB measurement network (Programa Meteorología, 2011) located at $00^{\circ} 20^{\prime} 09^{\prime \prime}$ W $39^{\circ} 27^{\prime} 49^{\prime \prime} \mathrm{N}$, on a flat roof without obstructions or shade on a building in the city of Valencia. 
The sensor is a UVB-1 YES model broadband radiometer that measures in the range 280-400 $\mathrm{nm}$ by providing a single integrated value for the whole measurement range. The instrument response is similar to the erythemal action spectrum, so that the sensor is capable of measuring the biologically effective solar UVR.

The measuring station also includes a stabilised uninterruptible power supply, a mast assembly platform for the radiometer, a communication antenna, and a compartment for elements with pre-installation of electrical and mechanical components. The UVB-1 pyranometer is designed to be stable for long periods and for field work without supervision. The calibration uncertainty is approximately $10 \%$. The cosine response is less than $4 \%$ for solar zenith angles below $55^{\circ}$ (manufacturer's specifications). Calibration consists of measuring the spectral response of the radiometer indoors and a comparison with a Brewer MKIII spectroradiometer outdoors (Hulsen and Grobner, 2007; Vilaplana et al., 2006).

It should be noted that the YES UVB-1 presents non-negligible errors for high zenith angles unless a double entry zenith angle-ozone calibration matrix is used (Vilaplana et al., 2006). For a constant ozone value of $300 \mathrm{DU}$, the error given by the calibration matrix remained below $9 \%$ for zenith angles below $70^{\circ}$. Additional calibration of this radiometer was carried out by the Earth Physics Department of the UV by comparison with an Optronic OL-754 spectroradiometer equipped with a double monochromator with a spectral range that extends from $250 \mathrm{~nm}$ to $800 \mathrm{~nm}$. The values given by the Optronic spectroradiometer were convolved with the erythemal action spectrum and then integrated and compared with the values obtained from the UVB-1 (Cañada et al., 2008; Tena et al., 2009).

\section{UV exposure limits}


The International Radiation Protection Association established exposure limits (EL) in its recreational/occupational UV exposure standard in 1985 (IRPA, 1985). These were later adopted by the International Commission on Non-Ionizing Radiation Protection and updated in 2010 (ICNIRP, 2010). The ICNIRP recommends a maximum personal daily exposure of 30 $\mathrm{J} / \mathrm{m}^{2}$ effective UV dose within an 8-hour period for sensitive unprotected skin using the American Conference of Governmental Industrial Hygienists (ACGIH) action spectrum (ICNIRP, 2007). This limit is equivalent to approximately 1.0-1.3 SED using the CIE action spectrum (ACGIH, 1999).

However, the ICNIRP report (2007) also found that skin adapts to frequent UV exposure not only by the obvious effect of skin darkening but also by increasing its thickness, which can lead to a significant increase in UV protection by a factor of five or greater.

According to ICNIRP (2010) for Mediterranean subjects with skin phototype III/IV a value of 12 SED is assumed to be the average threshold exposure for sunburn of sun-adapted skin. For the same type of skin but without adaptation a value of 5 SED is adopted. Exposure higher than 12 SED denotes high risk.

The exposure measured in the workers in our study was compared with the value of 12 SED, since we considered that due to their work they already had sun-adapted skin. It was also compared with the EL value.

\section{Skin Exposure factor}

A semi-quantitative hazard assessment for outdoor workers can be provided by using a skin exposure factor (EF), as reported by ICNIRP, 2007:

Skin Exposure factor $=f_{1} f_{2} f_{3} f_{4} f_{5} f_{6}$ 
where $f_{l}$ is the factor indicating geographical latitude and season, $f_{2}$ is the cloud cover, $f_{3}$ is the duration of exposure, $f_{4}$ is the ground reflectance, $f_{5}$ refers to clothing and $f_{6}$ to shade.

The values adopted for this study were the following:

$f_{l}=7$ (mid-latitudes in summer) $f_{2}=1$ (clear sky); $f_{3}=1$ (all day); $f_{4}=1$ (various surface);

$f_{5}=0.5$ (trunk protected but arm exposed); $f_{6}=1$ (no shade).

Skin EF was determined for the building workers and was compared with the guide suggested by ICNIRP (2007) to ascertain the minimal level of protection required for the workplace.

\section{Statistical analysis}

Data were analysed using the Statgraphics Plus Statistical Package v5.1 software and are expressed as median (minimum-maximum). The Mann-Whitney test (Wilcoxon) was used to compare differences between subjects in terms of SED, SED per hour outdoors and ER. Statistical significance was set at $\mathrm{p} \leq 0.05$ for all analyses.

\section{Results}

Ambient solar UVER

Measurements of daily ambient solar UVER were recorded by the radiometer at the GV station. These are shown in Table 1 for each day of the study.

Also shown in Table 1 is the actual temperature data provided by the State Agency for Meteorology (AEMET, 2011), ozone data from the Ozone Monitoring Instrument (OMI), (NASA, 2011) and the maximum ultraviolet index (UVI) (ICNIRP, 1995; WHO, 2002) calculated from the noonday UVER $\left(\mathrm{W} / \mathrm{m}^{2}\right)$ measurements at the local weather station for the entire period of the study. 
As shown in Table 1, solar UVI is quite high, between 8 and 9, and is characteristic of the summer figures in Valencia. The total column ozone from the OMI measurements for Valencia is between 315 to 325 D. U. Mean solar height at noon in Valencia during the study period was 72.8 degrees.

$<$ Table 1>

\section{Measured UVER exposures}

Table 2 shows the recorded median daily dosimeter exposures, $6.11(0.98-24.5)$ SED. Per hour outdoors was $0.68(0.10-2.56) \mathrm{SED}$, where data are expressed as median (minimummaximum). The exposure ratio (ER) was also calculated, defined as the ratio between the personal dose on a selected anatomical site and the corresponding ambient dose on a horizontal plane during the same day. Table 2 lists the median of the exposures recorded for the corresponding day as a percentage of the measured daily total ambient UVER. Median ER for the entire study period was $13.9 \%(2.3-55.0)$.

\section{$<$ Table 2>}

The UVER exposure received on the first and last day of the study is twice that received on the remaining days, as is the exposure ratio (see Table 2).

The range gives information about how spread out the data is. Daily range gives a measure of the variability between subjects. On July $8,12^{\text {th }}$ and $13^{\text {th }}$ the UVER exposure range is twice that of the others two days, indicating that on those days, the individuals present less consistent behaviour with respect to their activities.

$<$ Table 3> 
Table 3 show the median UVER exposure and exposure relative to ambient for each worker. The variation between the different subjects is of interest, since there are differences between individuals due to their different occupations on the building site. Some of the lowest exposures were found in the foremen, who spent some time under cover. The occupations with the highest UVER exposures were found in those who spent most of their time in sunlight and included the formworkers and the steel fixer. The latter received a UVER dose two to three times higher than the rest. The range for each worker gives a measure of the variability in each subject. The formworkers and steel fixer present a range of UVER exposure twice that of the others, indicating that their occupations presented less consistent behaviour than the other activities.

$<$ Table 4>

The results discussed above are sub-classified by dosimeter position in Table 4. No significant difference was found in terms of SED received $(\mathrm{p}=0.92)$, SED per hour $(\mathrm{p}=0.92)$ or ER $(\mathrm{p}=0.99)$ regarding the dosimeter position, using the Mann-Whitney (Wilcoxon) test to compare medians.

\section{Skin Exposure Factor}

The application of this term gives a result of 3.5, in accordance with the values adopted for the study. According to the guide suggested by ICNIRP (2007) the workers involved in this study should use long-sleeved shirt, trousers, brimmed hat and SPF15+ sunscreen to reduce skin exposure.

$<$ Table 5> 


\section{Discussion}

A number of studies have measured UVR exposure in building workers. Milon et al., 2007 studied the effective exposure to solar UVR in building workers in the Swiss Alps in the summer, in which mean concurrent (during the same exposure period) ER ranged between $27 \%$ and $54 \%$, measured at five positions on the body. Our median ER measured on two parts of the body ranged between $2 \%$ and $55 \%$ and was calculated for a 24 h. period.

Hammond et al., 2009 reports the summer UVR exposure among a sample of outdoor workers in New Zealand. For building workers, the mean daily concurrent ER was $19.6 \%$ on the back, with a range of 1.6 to 66.4 , whereas we obtained a median ER of $14.5 \%$ (range 2.3-55.0) on the shoulder (comparable to the back area).

Gies and Wright, 2003 examined UVR exposure in some groups of outdoor workers related to the construction industry in Australia in the spring. They found that a formworker received a median concurrent ER of $30 \%$ and a steel fixer of $33 \%$, both on the chest, whereas we measured a median ER of $9 \%$ and $42 \%$, respectively, on the chest. For foremen, they found a median concurrent ER of $18 \%$, while we obtained a median ER of 11-14\%. Except for the formworkers, the values can be considered similar.

In other outdoor occupations, Schmalwieser et al., 2010 studied facial solar UV exposure of Austrian farmers and found that they receive on average an ambient daily dose between of $3 \%$ and $26 \%$. Siani et al., 2011 quantify the UV exposure of vineyard workers in Italy, who in summer received a median concurrent ER of $29 \%$ on the arm and $50 \%$ on the back. Gies et al., 2009 measured the UVR exposure of Antartic workers on the chest in summer and obtained a mean ER ranging from 9 to $20 \%$. 
A study or gardeners in Ireland and Denmark (Thieden et al., 2005) found median ER values ranging from $4.5 \%$ to $8 \%$. We conducted a previous study (Serrano et al., 2009) comparing the UV dose received by gardeners and lifeguards and recorded ER values of $9 \%$ and $27 \%$, respectively.

The median daily UV exposure for building workers in our study was $6.11 \mathrm{SED}$, which therefore exceeded the EL by a factor of 6, so that the individuals engaged in these activities received 6 times the expected occupational UVER load for outdoor workers. This outdoor group thus had measured UVER exposures in excess of occupational guidelines, indicating that protective measures are highly advisable.

The skin exposure factor calculated for this study gave us a result of 3.5. In accordance with ICNIRP (2007) recommendations these workers should use long-sleeved shirt, trousers, brimmed hat and SPF15+ sunscreen.

This organisation also found that the skin adapts to frequent UV exposure and can significantly increase UV protection by a factor of five or more (ICNIRP, 2010).

For Mediterranean subjects with skin phototype III/IV a value of 12 SED is assumed to be the average threshold exposure for sunburn in sun-adapted skin type III/IV (ICNIRP, 2010). According to the above results, the median UVER exposure of the workers in this study does not exceed the recommended threshold value.

The building workers in this study received a median of $13.9 \%$ ambient UVER, with a range between 2.3 and 55\%, and a median daily UV exposure of 6.11 SED, with a range between 1 SED and 24.5 SED. Such a large range in both measurements could be caused by different orientation of the dosimeters relative to the horizontal, due to the different postures adopted by the workers and their orientation on the site, as was also observed by Milon et al., 2007. The 
effect of the different working locations can also be important, since the foremen, who spent some time in the shade, had lower exposures, while the formworkers and steel fixer, who spent most of their time exposed to sunlight, had the highest UVER exposures. We also found that the activities of these workers presented less consistent behaviour than the other activities.

There are two days when both the UVER exposure and the exposure ratio are twice that of the other days, indicating that the various individuals did not display consistent behaviour on these dates, probably due to a different working location, or possibly because ambient UVR was higher on these two days.

Since building workers can spend up to $9 \mathrm{hr}$ per day exposed to UVR, it is not possible for this population to completely avoid UV exposure, so that the use of sunscreens, sunglasses and protective clothing are advisable protective strategies.

In conclusion, a personal VioSpor film dosimeter was used to measure the occupational UV exposure of building workers, who were found to far exceed occupational UV exposure limits (ICNIRP, 2010). It is therefore clear that permanent and constant exposure to solar radiation without protection by outdoor workers involves a notable risk factor and can be assumed to be associated with skin cancer.

\section{Acknowledgments}

The authors wish to thank the UPV building staff for their cooperation in this study. We are also grateful to the State Agency for Meteorology and the Generalitat Valenciana for providing us with access to their meteorological data.

We would like to thank the R\&D\&I Linguistic Assistance Office, Universidad Politécnica de Valencia (Spain) for granting financial support for proof-reading this paper. 
This research was supported by the Spanish Ministry of Education and Science within the research project CGL2010-15931 and the Generalitat Valenciana within project PROMETEO/2010/064. 


\section{REFERENCES}

Aceituno-Madera P., Buendía-Eisman A. Olmo F.J., Jiménez-Moleón J.J. and Serrano-Ortega S. Melanoma, Altitude, and UV-B Radiation. Actas Dermosifiliogr. 2011: 102(3):199-205.

ACGIH, TLVs and BEI: threshold limit values for chemical substances and physical agents, biological exposure indices. Cincinnati: American Conference of Governmental Industrial Hygienists 1999: 154-158.

Agencia Estatal de Meteorología (AEMET). Available at http://www.aemet.es/. Accessed on 7 March 2011.

Bauer A., Diepgen T.L. and Schmitt J. A systematic review and meta-analysis of the epidemiological literature: Is occupational solar ultraviolet irradiation a relevant risk factor for basal cell carcinoma?. British Journal of Dermatology 2011: 165: 612-625.

Biosense Laboratories. Available at www.biosense.de/home-e.htm. Accessed on 11 April 2011.

Birch-Johansen F., Jensen A., Mortensen L., Braae A. and Kjær S.K. Trends in the incidence of nonmelanoma skin cancer in Denmark 1978-2007: rapid incidence increase among young Danish women. Int. J. Cancer 2010: 127: 2190-2198. 
Boniol M., De Vries E., Coebergh J.W. and Dore J.F. Seasonal variation in the occurrence of cutaneous melanoma in Europe: influence of latitude. An analysis using the EUROCARE group of registries. European Journal of Cancer 2005: 41: 126-132.

Cabanes A. , Pérez-Gómez B., Aragonés N., Pollán M. and López-Abente G. La situación del cáncer en España, 1975-2006. Madrid: Instituto de Salud Carlos III, 2009.

Cáncer en cifras. Centro Nacional de Epidemiología Instituto de Salud Carlos III http://193.146.50.130/morta/grafs.php\#grafs. Accessed on 15 June 2011.

Cañada J., Esteve A.R., Marin M.J., Utrillas M.P., Tena F., and Martinez-Lozano J.A.Study of erythemal, UV(A+B) and global solar radiation in Valencia (Spain). International Journal of Climatology 2008: 28: 693-702.

CAREX project http://www.esf.org/research-areas/space-sciences/activities/carex-project.html. Accessed on 15 June 2011.

Chang Y., Barrett J.H. and Timothy D. Sun exposure and melanoma risk at different latitudes: a pooled analysis of 5700 cases and 7216 controls. International Journal of Epidemiology 2009: 38: 814-830.

CIE, International Commission on Illumination, Standard Erythema Dose, a Review. CIE Journal 1997 : 125, Vienna. 
de Gruijl F.R. Sufficient Vitamin D from Casual Sun Exposure?. Photochemistry and Photobiology 2011: 87: 598-601.

de Vries E., Boniol M., Dore J.F. and Coebergha J.W.W. Lower incidence rates but thicker melanomas in Eastern Europe before 1992: a comparison with Western Europe. European Journal of Cancer 2004: 40: 1045-1052.

de Vries E., Tyczynski J.E. and Maxwell Parkin D. Cutaneous malignant melanoma in Europe. European network of cancer registries. International agency for research on cancer ENCR CANCER FACT SHEETS No. 4, November 2003.

Downs N. J., Schouten P.W., Parisi A.V. and Turner J. Measurements of the upper body ultraviolet exposure to golfers: non-melanoma skin cancer risk, and the potential benefits of exposure to sunlight Photodermatology, Photoimmunology \& Photomedicine 2009: 25: 317324.

Downs N., Parisi A. and Schouten P. Basal and squamous cell carcinoma risks for golfers: An assessment of the influence of tee time for latitudes in the Northern and Southern hemispheres. Journal of Photochemistry and Photobiology B: Biology 2011: 105: 98-105.

EUROMELANOMA. Available at http://www.euromelanoma.org. Accessed on 5 April 2011. 
Fuglede N.B., Brinck-Claussen U., Deltour I., Boesen E.H., Dalton S.O. and Johansen C. Incidence of cutaneous malignant melanoma in Denmark,1978-2007. British Journal of Dermatology 2011: 165: 349-353.

Furusawa Y., Quintern L.E., Holtschmidt H., Koepke P. and Saito M. Determination of erythemaeffective solar radiation in Japan and Germany with a spore monolayer film optimized for the detection of UVA and UVA - results of a field campaign. Appl. Microbiol. Biotechnol. 1998: 50: 597-603.

Garbe C. and Leiter U. Melanoma epidemiology and trends. Clinics in Dermatology 2009: 27: 39.

Gies P. and Wright J. Measured Solar Ultraviolet Radiation Exposures of Outdoor Workers in Queensland in the Building and Construction Industry. Photochemistry and Photobiology 2003: 78(4): $342-348$.

Gies P., Watzl R., Javorniczky J., Roy C., Henderson S., Ayton J. and Kingston M. Measurement of the UVR Exposures of Expeditioners on Antarctic Resupply Voyages. Photochemistry and Photobiology 2009: 85: 1485-1490.

Gilbert R., Metcalfe C., Oliver S.E., Whiteman D.C., Bain C., Ness A. et al. Life course sun exposure and risk of prostate cancer: population-based nested case-control study and metaanalysis. Int. J. Cancer. 2009: 125:1414-1423. 
Glanz K., Buller D.B. and Saraiya M. Reducing ultraviolet radiation exposure among outdoor workers: State of the evidence and recommendations. Environmental Health 2007: 6:22.

GLOBOCAN 2008. World Health Organization, International Agency for Research on Cancer. http://globocan.iarc.fr/. Accessed on 15 June 2011.

Grant W.B. Relation between prediagnostic serum 25-hydroxyvitamin D level and incidence of breast, colorectal, and other cancers. Journal of Photochemistry and Photobiology B: Biology 2010: 101: 130-136.

Grant W.B. and Holick M.F. Benefits and requirements of vitamin D for optimal health: a review. Alternative Medicine Review 2005: 10(2): 94-104.

Hakansson N., Floderus B., Gustavsson P., Feychting M. and Hallin N. Occupational sunlight exposure and cancer incidence among Swedish construction workers. Epidemiology 2001: 12: $552-557$.

Hammond V., Reeder A.I. and Gray A. Patterns of real-time occupational ultraviolet radiation exposure among a sample of outdoor workers in New Zealand. Public Health 2009: 123: 182-187.

Hülsen G. and Gröbner J. Characterization and calibration of ultraviolet broadband radiometers measuring erythemally weighted irradiance. Appl. Opt. 2007: 46: 5877-5886. 
Humble M.B. Vitamin D, light and mental health. Journal of Photochemistry and Photobiology B: Biology 2010: 101: 142-149.

IARC Monographs. Evaluation of carcinogenic risks to humans: solar and ultraviolet radiation 55, Lyon, 2000.

IRPA (International Radiation Protection Association) Guidelines on Limits of Exposure to Ultraviolet Radiation of Wavelengths between $180 \mathrm{~nm}$ and 400nm (Incoherent Optical Radiation). Health Physics 1985: 49(2): 331-340.

ICNIRP (International Commission on Non-Ionizing Radiation Protection) Protection of Workers against Ultraviolet Radiation. Health Physics 2010: 99(1): 66-87.

ICNIRP (International Commission on Non-Ionizing Radiation Protection) Protecting Workers from Ultraviolet Radiation (Edited by P. Vecchia, M. Hietanen, B. E. Stuck, E. van Deventer and S. Niu), ICNIRP14/2007. ICNIRP, Oberschleissheim, Germany.

ICNIRP (International Commission on Non-Ionizing Radiation Protection) Global Solar UV Index. ICNIRP-1/95.

John E.M., Koo J. and Schwartz G.G. Sun exposure and prostate cancer risk: evidence 
for a protective effect of early-life exposure. Cancer Epidemiol Biomarkers Prev. 2007: 16:12831286.

Kampman M.T. and Steffense L.H. The role of vitamin D in multiple sclerosis. Journal of Photochemistry and Photobiology B: Biology 2010: 101: 137-141.

Kauppinen T., Toikkanen J., Pedersen D., Young R., Kogevinas M., Ahrens W. et al. Occupational exposure to carcinogens in the European Union in 1990-1993. CAREX. International information system on Occupational Exposure to Carcinogens. Helsinki: Finnish Institute of Occupational Health, 1998.

Kenborg L., Jørgensen A. D., Budtz-Jørgensen E., Knudsen L.E. and Hansen J. Occupational exposure to the sun and risk of skin and lip cancer among male wage earners in Denmark: a population-based case-control study. Cancer Causes Control 2010: 21: 1347-1355.

Lichte V., Dennenmoser B., Dietz K., Hafner H.M., Schlagenhauff B., Garbe C. and Fischer J. Professional risk for skin cancer development in male mountain guides - a cross-sectional study. Journal of the European Academy of Dermatology and Venereology 2010: 24: 797-804.

Lucas R., McMichael T., Smith W. and Armstrong B. Solar ultraviolet radiation: Global burden of disease from solar ultraviolet radiation. Prüss-Ustün A et al., eds. Geneva, World Health Organization, 2006 (Environmental Burden of Disease Series, No. 13). 
Madan V., Lear J. and Szeimies R.M. Non-melanoma skin cancer. Seminar www.thelancet.com February 20, 2010: 375.

Maqueda J., De la Orden V., Kauppinen T., Toikkanen J., Pedersen D., Young R. et al. Occupational exposure to carcinogens in Spain in 1990-1993: preliminary results. Helsinki: Finnish Institute of Occupational Health, 1998.

McKinlay A.F. and Diffey B.L. A reference action spectrum for ultraviolet induced erythema in human skin. CIE Journal 1987: 6: 17-22.

Medhaug I., Olseth J.A. and Reuder J. UV radiation and skin cancer in Norway. Journal of Photochemistry and Photobiology B: Biology 2009: 96: 232-241.

Micu E., Juzeniene A. and Moan J. Comparison of the time and latitude trends of melanoma incidence in anorectal region and perianal skin with those of cutaneous malignant melanoma in Norway. Journal of the European Academy of Dermatology and Venereology 2011, DOI: 10.1111/j.1468-3083.2011.04023.x

Milon A., Sottas P.E., Bulliard J.L. and Vernez D. Effective exposure to solar UV in building workers: influence of local and individual factors. Journal of Exposure Science and Environmental Epidemiology 2007: 17: 58-68.

Moehrle M. and Garbe C. Does mountaineering increase the incidence of cutaneous melanoma? A 
hypothesis based on cancer registry data Dermatology. Dermatology 1999: 199(3): 201-203.

Moehrle M., Dennenmoser B. and Garbe C. Continuous long-term monitoring of UV radiation in Professional mountain guides reveals extremely high exposure. Int. J. Cancer 2003: 103: 775778.

Moehrle M., and Garbe C. Personal UV dosymetry by Bacillus subtilis Spore Films. Dermatology 2000: 200: 1-5.

Munakata N., Kazadzis S., Bais A.F., Hieda K., Ronto G., Rettberg P. and Horneck G.. Comparisons of Spore Dosimetry and Spectral Photometry of Solar-UV Radiation at Four Sites in Japan and Europe. Photochemistry and Photobiology 2000: 72(6): 739-745.

NASA. Total Ozone Mapping Spectrometer. Available at http://jwocky.gsfc.nasa.gov/ Accessed on 7 March 2011.

Norval M., Cullen A.P., de Gruijl F.R., Longstreth J., Takizawa Y., Lucas R.M., Noonan F.P. and Van der Leun J. C. The effects on human health from stratospheric ozone depletion and its interactions with climate change. Photochem. Photobiol. Sci. 2007: 6: 232-251.

O’Riordan D.L., Glanz K., Gies P. and Elliott T. A Pilot Study of the Validity of Self-reported Ultraviolet Radiation Exposure and Sun Protection Practices Among Lifeguards, Parents and Children. Photochem. Photobiol. 2008: 84(3): 774-778. 
Pfeifer M.T., Koepke, P. and Reuder, J. Effects of altitude and aerosol on UV radiation.

Journal of Geophysical Research D: Atmospheres 2006: 111(1).

Programa meteorología de la Fundación Centro de Estudios Ambientales del Mediterráneo

(Generalitat Valenciana). http://www.gva.es/ceamet/vigilancia/radUV/radUV.html. Accessed on 2

$\underline{\text { March } 2011}$

Quintern L.E., Furusawa Y., Fukutsu K. and Holtschimdt H. Characterization and application of UV detector spore-films: the sensitivity curve of a new detector system provides good similarity to the action spectrum for UV-induced erythema in human skin. J. Photochem. Photobiol. B:Biology 1997: 37: 158-166.

Radespiel-Tröger M., Meyer M., Pfahlberg A., Lausen B., Uter W. and Gefeller O. Outdoor work and skin cancer incidence: a registry-based study in Bavaria. Int. Arch. Occup. Environ. Health 2009: 82:357-363.

Schmalwieser A.W., Cabaj A., Schauberger G., Rohn H., Maier B. and Maier H. Facial Solar UV Exposure of Austrian Farmers During Occupation. Photochemistry and Photobiology 2010: 86: $1404-1413$.

Seckmeyer G., Mayer B. and Bernhard G. The 1997 Status of Solar UV Spectroradiometry in Germany: Results from the National Intercomparison of UV Spectroradiometers, with 
contributions from Albold A., Baum W., Dehne K., Feister U.,Gericke K., Grewe R., Gross C., Sandmann H., Schreiber J., Seidlitz H.K., Steinmetz M., Thiel S., Wallasch M. and Weller M.. Garmisch-Partenkirchen, Germany, Fraunhofer Institute for Atmospheric Environmental research 1998: 55/98, ISBN: 3-8265-3695-9.

Serrano M.A., Cañada J., Moreno J.C. Erythemal Ultraviolet exposure in two groups of outdoor workers in Valencia, Spain. Photochemistry and Photobiology 2009: 85: 1468-1473.

Siani A.M., Casale G.R., Di’emoz H., Agnesod G., Kimlin M.G., Lang C.A. and Colosimo A. Personal UV exposure in high albedo alpine sites. Atmos. Chem. Phys. 2008: 8: 3749-3760.

Siani A.M., Casale G.R., Sisto R., Colosimo A., Lang C.A. and Kimlin M.G. Occupational Exposures to Solar Ultraviolet Radiation of Vineyard Workers in Tuscany (Italy) Photochemistry and Photobiology 2011: 87: 925-934.

Tena F., Martinez-Lozano J.A., Utrillas M.P., Marin M.J., Esteve A.R. and Cañada J. The erythemal clearness index for Valencia, Spain. International Journal of Climatology 2009: 29: $147-155$.

Thieden E., Collins S.M., Philipsen P.A., Murphy G.M. and Wulf H.C. Ultraviolet exposure patterns of Irish and Danish gardeners during work and leisure. British Journal of Dermatology 2005: 153:795-801. 
Van Amerongen B.M., Dijkstra C.D., Lips P. and Polman C.H. Multiple sclerosis and vitamin D: an update. Eur. J. Clin. Nutr. 2004: 58:1095-1109.

Vilaplana, J.M., Cachorro V.E., Sorribas M., Luccini E., de Frutos A.M., Berjón A. et al. Modified calibration procedures for a Yankee Environmental System UVB-1 biometer based on spectral measurements with a Brewer spectrophotometer. J. Photochem. Photobiol. 2006: 82: 508-514.

Webb A.R., Kift R., Berry J.L. and Rhodes L.E. The Vitamin D Debate: Translating Controlled Experiments into Reality for Human Sun Exposure Times. Photochemistry and Photobiology 2011: 87: 741-745.

World Health Organization. Global Solar UV Index: A Practical guide. WHO 2002, Geneva, Switzerland.

World Cancer Report 2008. World Health Organization, International Agency for Research on Cancer. Edited by Peter Boyle and Bernard Levin, Lyon 2008.

Zittermann A. and Gummert J.F. Sun, vitamin D, and cardiovascular disease. Journal of Photochemistry and Photobiology B: Biology 2010: 101: 124-129. 
Table 1. Actual mean temperature (with maximum and minimum in brackets) data of ozone concentration from ozone monitoring instrument (NASA), ambient UVER and UV index from the UVER $\left(\mathrm{W} / \mathrm{m}^{2}\right)$ YES UVB-1 radiometer at the official Valencia weather station.

\begin{tabular}{lcccc}
\hline Date & $\begin{array}{c}\text { Air temperature } \\
\left({ }^{\circ} \mathrm{C}\right)\end{array}$ & $\begin{array}{c}\text { Ozone } \\
(\text { Dobson Units })\end{array}$ & $\begin{array}{c}\text { Ambient UVER } \\
\left(\mathrm{J} / \mathrm{m}^{2}\right)\end{array}$ & UVI \\
\hline $07 / 07 / 2010$ & $25.0(27.9-21.3)$ & 315 & 5124.0 & 9 \\
$08 / 07 / 2010$ & $25.1(28.3-21.5)$ & - & 4462.3 & 8 \\
$09 / 07 / 2010$ & $25.5(28.6-21.9)$ & 325 & 4574.6 & 8 \\
$12 / 07 / 2010$ & $25.6(29.6-21.7)$ & 314 & 4203.9 & 8 \\
$13 / 07 / 2010$ & $25.4(28.3-21.7)$ & - & 4713.7 & 8 \\
\hline
\end{tabular}


Table 2. UVER exposure (given in SED) measured using Viospor dosimeters and building workers' exposure ratio.

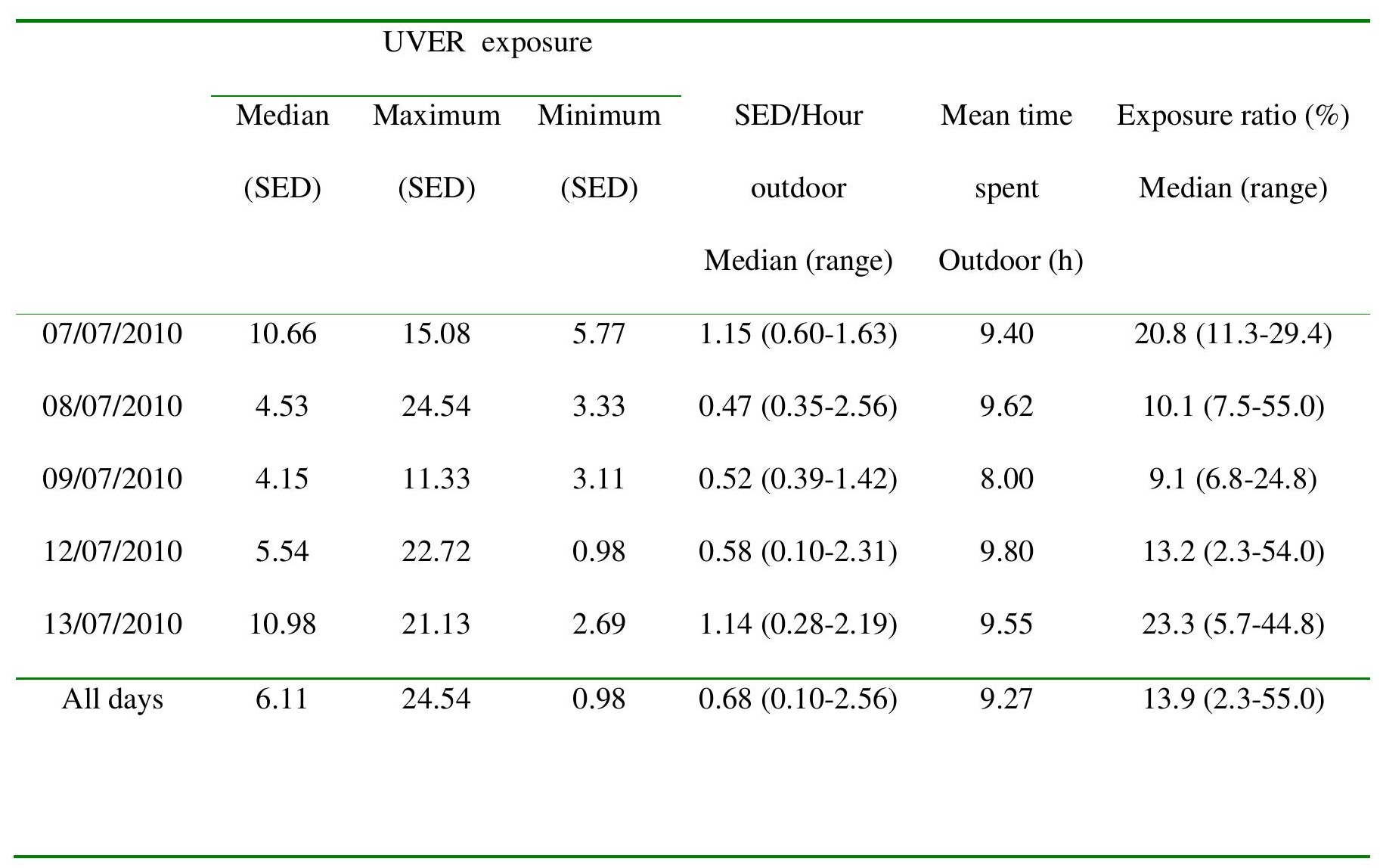


Table 3. Building workers' UVER exposure given in SED - measured using individual Viospor dosimeters.

\section{UVER exposure}

\begin{tabular}{|c|c|c|c|c|c|c|}
\hline Subject (number & Mean time & & & & & \\
\hline chest dosimeter- & spent & (SED) & (SED) & (SED) & outdoor & Median (range) (\%) \\
\hline shoulder dosimeter) & Outdoor (h) & & & & Median (range) & \\
\hline Steel fixer (1-0) & 9.30 & 18.76 & 22.72 & 3.27 & $1.93(0.41-2.31)$ & $42.0(7.2-54.0)$ \\
\hline Formworkers(1-2) & 9.28 & 8.72 & 24.54 & 1.53 & $0.96(0.15-2.56)$ & $17.4(3.6-55.0)$ \\
\hline Formwork foreman & 9.33 & 6.38 & 12.83 & 4.61 & $0.74(0.47-1.33)$ & $13.9(10.3-25.0)$ \\
\hline$(1-0)$ & & & & & & \\
\hline Site foreman (1-0) & 9.15 & 5.22 & 5.77 & 3.11 & $0.56(0.35-0.61)$ & $11.3(6.8-12.4)$ \\
\hline Security officers & 9.28 & 6.6 & 17.78 & 0.98 & $0.70(0.10-1.83)$ & $14.1(2.3-37.7)$ \\
\hline$(0-2)$ & & & & & & \\
\hline All workers & 9.27 & 6.11 & 24.54 & 0.98 & $0.68(0.10-2.56)$ & $13.9(2.3-55.0)$ \\
\hline
\end{tabular}


Table 4. UVER exposures (given in SED) measured using Viospor dosimeters and exposure ratio for the different position of the dosimeters on building workers.

\begin{tabular}{|c|c|c|c|c|c|c|}
\hline & \multicolumn{3}{|c|}{ UVER exposure } & \multirow[b]{2}{*}{ SED/Hour } & \multirow[b]{2}{*}{ Mean time } & \multirow[b]{2}{*}{ Exposure ratio } \\
\hline & Median & Maximum & Minimum & & & \\
\hline & (SED) & (SED) & (SED) & outdoor & spent & $(\%)$ \\
\hline & & & & Median (range) & Outdoor (h) & Median (range) \\
\hline Chest & 5.71 & 22.72 & 1.53 & $0.60(0.15-2.30)$ & 9.58 & $12.2(3.6-54.0)$ \\
\hline Shoulder & 7.41 & 24.54 & 0.98 & $0.78(0.10-2.56)$ & 9.58 & $14.5(2.3-55.0)$ \\
\hline
\end{tabular}


Table 5. Skin exposure factor (EF) and skin protection factor as reported by ICNIRP.

\begin{tabular}{cc}
\hline EF & Skin protection Factor \\
\hline$<1$ & None \\
\hline$>1$ but $<3$ & Shirt, brimmed hat \\
\hline$>3$ but $<5$ & Long-sleeved shirt, trousers, brimmed hat, SPF15+ sunscreen \\
$>5$ & Long-sleeved shirt, trousers, brimmed hat, SPF15+sunscreen. Modify work \\
& environment \& practices, try to create some shade. \\
\hline
\end{tabular}

